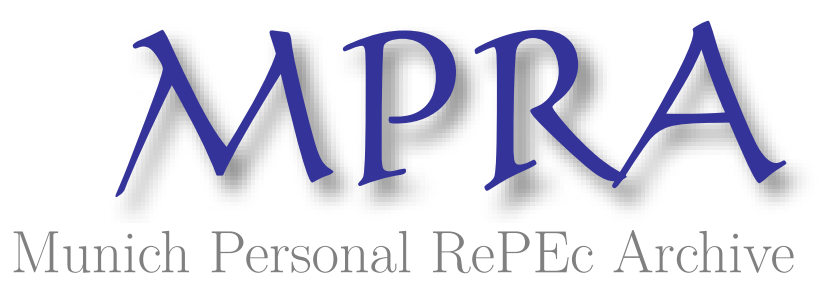

\title{
Eliciting environmental preferences of Ghanaians in the laboratory: An incentive-compatible experiment
}

Meroz, Yael and Morone, Andrea and Morone, Piergiuseppe

4 September 2009

Online at https://mpra.ub.uni-muenchen.de/17107/

MPRA Paper No. 17107, posted 05 Sep 2009 07:33 UTC 


\title{
Eliciting environmental preferences of Ghanaians in the laboratory: An incentive-compatible experiment ${ }^{\star}$
}

\author{
Yael Meroz \\ University of Foggia \\ y_meroz@yahoo.it
}

\author{
Andrea Morone \\ University of Bari \\ a.morone@gmail.com
}

\author{
Piergiuseppe Morone \\ University of Foggia \\ p.morone@gmail.com
}

\begin{abstract}
In this paper we aim to look into the attributes of Ghanaians' willingness-to-pay for green products. This would help us to assess whether Ghanaians show a preference towards environmental goods. The methodology employed to address these issues is an 'experimentally-adapted' CV survey which involves laboratory experiment conducted among Ghanaian University students. Notwithstanding the limitations arising from the sample used in our experiment (most notably University students do not represent, economically wise, the entire Ghanaian population), we believe that our investigation provides a first answer to such question as Ghanaians consistently show that they are willing to pay an extra premium for green products.
\end{abstract}

JEL codes: C9; Q5

Keywords: contingent valuation, experiment, incentive-compatible, Ghana, organic products, willingness to pay.

Abbreviations: CV, WTP, WTA, BDM, CE

\footnotetext{
- We are grateful to Maria Vittoria Levati for helpful suggestions and comments. We also benefited from comments made by Beppe Celi. For their hospitality we thank the Department of Geology at the University of Legon in Ghana, and particularly Thomas Akabzaa for helping with the recruitment of students for the experiments, and Humphrey Akanaba for assisting in their conduction. The financial support provided by the Max Planck Institute and the University of Bari is gratefully acknowledged. We finally wish to thank all participants in the Brown Bag seminar at the Max Planck Institute of Economics, Strategic Interaction Group, for comments and suggestions and particularly Werner Güth. The usual disclaimers apply.
} 


\section{Introduction}

The idea that consumers are among the strongest actors in market economy is as old as the study of Economics. ${ }^{1}$ The idea, however, that consumers also hold power to influence production patterns and direct them into being more environmentally-friendly, expressing, on the market, their willingness to pay a higher premium for products which generate smaller environmental damage has emerged with the rise of the environmental movement in the 1970s, gaining momentum only in the last two decades or so. ${ }^{2}$

In order to assess the extra premium that consumers are willing to pay for green products or services, which typically have no real markets, environmental economics has developed several methods. Among such techniques we can list the hedonic prices method, the travel cost method, the contingent valuation (CV) method and the elicitation of the willingness to pay (WTP) for an environmental good or service or, alternatively, willingness to accept compensation (WTA) for environmental damage or for the loss of an environmental good or service. ${ }^{3}$

In this paper we will tackle this very issue concentrating our attention on less developed countries (LDCs). Specifically, we shall consider the Ghanaian case study, trying - through a laboratory experiment - to look into the attributes of a group of Ghanaian students' willingness to pay for green products (an organic banana in our case). Using the Experimental Economics technique, this study will try to answer the question whether in our experimental sample there is a tendency to attach a value to environmental goods or not.

\footnotetext{
${ }^{1}$ Hirschman (1970), for example, has divided consumer sanction power over corporate behaviour into three types: a positive sanction "loyalty", a negative sanction "exit" (terminating a business relationship) and "voice" (complaining or negative word-of-mouth).

${ }^{2}$ See, for instance, Kinnear and Taylor (1973); Martin and Simintiras (1995); and Prothero and McDonagh (1993). For example, it has been shown that US consumers may be willing to pay as high as 12 percent more for certified wood products, knowing that their purchase will contribute to the conservation or protection of forests (Ozanne and Vloskey, 2003).

${ }^{3}$ For a more thorough analysis of these methods, see Pearce and Turner (1990). It is worth-noting, though, that these techniques are used not only to estimate the value of "greener" market products, but also (and mainly) to elicit the value of non-market goods such as a beautiful landscape, clear air or an endangered species.
} 
In order to do so we will first briefly review the debate on environmental issues and less developed countries (section 2). After providing a brief review of the core theoretical issues (section 3), we will present a description of the experiment conducted at the University of Ghana at Legon (section 4) to be followed by the presentation and the interpretation of the obtained results (section 5). Section 6 contains some concluding remarks and suggestions for possible extensions of this work.

\section{Environment, contingent valuation and Developing Countries}

An inquiry into the demand for green products (or, more generally, into the issue of environmental concern) is quite common in the case of developed countries, where the willingness to pay for organic products was often investigated. ${ }^{4}$ However, in the case of LDCs, this field of study does not represent a very attractive research objective. In fact, many studies argue that this pattern of demand is very much correlated with the level of socioeconomic development (understood in terms of the level of GDP per capita). In other words, the assumption is that the demand (and with it, the willingness to pay) for products that are associated with more sustainable practices grows hand in hand with income. ${ }^{5}$

However, in the last 15 years or so CV has become a common method for the appraisal of WTA and WTP of the population in LDCs for improvement/worsening of environmental conditions (Carson et al., 1995). Indeed, there are obvious difficulties which the application of statedpreference techniques in LDCs presents, and in practical terms gathering correct and valuable

\footnotetext{
${ }^{4}$ See, for instance, Gil et al. (2000) for Spain; Boccaletti and Nardella (2000) for Italy, and Cranfield and Magnusson (2003) for Canada.

${ }^{5}$ The Environmental Kuznets Curve hypothesis, which suggests that environmental damage first rises with economic growth and then declines, is at the heart of this assumption. According to this hypothesis, environmental damage is bound to decline since the increase in economic indicators represents structural changes that lead the economy towards more information-intensive practices. This change is coupled with growing environmental awareness associated with post-modern societies - which gives rise to green consumerism. See Panayotou (1993), and Dasgupta et al. (2002).
} 
information (through polls, surveys, questionnaires or experiments) could be an extremely difficult and problematic task to accomplish in such a context. ${ }^{6}$

A prominent aim of this work is hence to test what we shall call the 'too poor to be green' hypothesis ${ }^{7}$ by means of an experimental analysis. Having in mind the nature of experiments (which are typically conducted among small groups of students), we are very much aware of the fact that our findings could hardly be generalised to the whole developing world or even to the single case of Ghana. ${ }^{8}$ Other possible shortcomings of the experimental approach relate to the considerations raised by Levitt and List (2007). More specifically, the authors pointed out that subjects in an experiment are usually not driven by solely monetary calculations, but also by at least five other factors, which should be taken into account in the analysis of the experiment's results: (1) the presence of moral and ethical considerations; (2) the nature and extent of scrutiny of one's actions by others; (3) the context in which the decision is embedded; (4) self-selection of the individuals making the decisions; (5) the stakes of the game.

Bearing in mind such possible biases, experiments can be designed to minimise them. Further, if the sign and plausible magnitude of the biases induced by the lab are known, one can extract useful information from a study, even if the results cannot be seamlessly extrapolated outside the lab. In this sense, even in cases where lab results are believed to have little 'generalizability', some number from a laboratory estimate is better than no number, provided that a theoretical model is used to make an appropriate inference. We now try to tackle this very problem, showing

\footnotetext{
${ }^{6}$ For a discussion on the technical difficulties and problems associated with the conduction of $\mathrm{CV}$ in developing countries, see Whittington (2002).

${ }^{7}$ Under the logic of 'too poor to be green' (as poignantly put by Martinez-Alier, 1995), some economists maintain that due to their low income level, developing countries' citizens do not have a preference for environmental goods (see, for instance, Wolf, 2004 or Thurow, 1980).

${ }^{8}$ Note that the issue of generalising experimental results is a mach debated one. See, for instance Smith (1976), Samuelson, (2005).
} 
that our experimental design overcomes many of the concerns pointed out by Levitt and List (2007).

When looking into point (1) we can argue that the growing debate on ethical values attached to organic production observable in most developed countries is fare from being an issue in a country like Ghana, where there is no real market for organic products; hence, the ethical aspects of organic production should not be a concern for our subject pool.

Concerning point (2), the experiment consisted in an individual decision making process and subjects' behaviour was able to influence their own pay-off only and never other subjects' decisions.

The third issue raised by Levitt and List could be a problem in an experiment addressing environmental issues. However, in the context of our experiment it should be stressed again that Ghanaians cannot have been biased in favour of organic bananas a-priori since there is no real market for organic products in the country.

As far as point (4) is concerned, it must be said that our experiment suffered from this problem less than experiments run in the US or in Europe as some of the people that participate in such experiments are 'experts', in the sense that they often take part in many other experiments - and this was not the case in our experiment.

Concerning point (5), we would like to underline that in our experiment we had a 'big stake', with subjects in a position to earn, in about an hour, goods (bananas) or moneys equivalent to as high as $5 \$$ which is roughly a daily salary in Ghana.

As already mentioned, information on the willingness to pay of consumers in developing countries for goods with more sustainable attributes is quite scarce. As also observed by Ara in a study about consumer WTP for organic rice in the Philippines, "a large number of consumer 
surveys on organic agricultural produce as well as food safety have been conducted in developed countries, yet the number of studies in developing countries is very limited" (Ara, 2003: 2). This observation is true also in the case of Ghana, where there are hardly any studies on this question. ${ }^{9}$ Indeed, organic food production in Ghana is quite limited. However, it has been steadily growing in the last years and various products (amongst them bananas, pineapples, tomatoes, coconuts, etc.), some for local consumption while others for export, have followed the organic production protocol to various extents (Scialabba, 2000; Willer and Yussefi, 2004). The organic product referred to in this study (bananas) is a case in point: VREL (Volta River Estates Limited), the organic bananas producer in Ghana, although relatively small, is currently one of the leading agricultural companies in the country and the only exporter of organic bananas. ${ }^{10}$

\section{Aim and Methodological Background of the Experiment}

As explained above, we address the issue of the poor and the environment by means of a laboratory incentive-compatible experiment which was conducted at the University of Ghana at Legon (Accra). Specifically, we attempt to test whether Ghanaians display a preference for green products (organic bananas) when compared to non-green products.

If proved to be true, this would allow us to infer that Ghanaians do have a preference for the environment and that they are willing to pay an extra premium in order to preserve it, hence countering the 'too poor to be green' argument. However, we should bear in mind that our

\footnotetext{
${ }^{9}$ Two exceptions are worth noting in the literature vacuum context: the first is of a study which examined consumers' WTP for tomatoes produced without chemicals. According to the study, which consisted in a household survey in various cities throughout Ghana, about 50 percent of urban households were willing to pay, on average, 80 percent more for organic food, 10 percent were indifferent and 40 percent believed that a price lower by 50 percent would be appropriate ${ }^{9}$ (IWMI, International Water Management Institute, cited in Danso et al., 2002). Other results were obtained by another study on consumer WTP for pesticide-free and germ-free fresh vegetables. In this case, on average, the sampled consumers in the capital Accra were willing to pay 20 percent more for a germ-free cabbage and almost 30 percent more for a pesticide-free one (Al-Hassan and Jatoe, 2005).

${ }^{10}$ See Siaw (2003). Here, it is worth mentioning that 15 percent of the produce is sold in big cities' markets in Ghana (with no particular tag or label) (see VREL's website).
} 
experiment is conducted among a small group of students which probably do not represent the average Ghanaian due to the high level of income inequality present in the country, hence we shall be very cautious in inferring any generalisation from our empirical findings.

We will attempt to estimate subjects' preferences using two alternative elicitation mechanisms. Specifically, we shall confront subject preferences elicited in a choice context and subject preferences elicited in a price context.

In the former case, the subject faces a choice between two different quantities of two goods (organic versus non-organic bananas, in our case); after having expressed his/her preference, the subject receives the good opted for. ${ }^{11}$

In the latter case subjects are asked to indicate their reservation price to buy a certainty amount of organic (non-organic) bananas. Note that the price context requires the implementation of the socalled BDM mechanism ${ }^{12}$ (Becker, DeGroot and Marschak, 1964). This specific incentive scheme was originally developed to construct a von Neumann-Morgenstern utility function by determining a series of certainty equivalent of binary lotteries. Here subjects are asked to state an amount of money such that they do not care whether they will receive this amount or the good. Then, a number $z$ is randomly drawn between 1 and $y$, where $y$ is higher than the value of the good in question. If $z$ is greater or equal to the amount stated by the subject, he/she receives $y$, otherwise he/she receives $y-z$ and the good itself.

\footnotetext{
${ }^{11}$ This should serve as a guarantee that subjects express their true preference.

12 There are two orders of reasons which support our decision to use BDM: first and foremost, Hey, Morone and Schmidt (2007) showed in a recent paper how (under the assumption that subjects have Expected Utility functions) "BDM performs better then ASK [WTA], which, in turn, performs better than BID [WTP]" (2007: 13); secondly, given the fact that at the University of Ghana there was no computer laboratory available to conduct the experiments, BDM turned to be more suitable for paper and pencil experiments.
} 


\section{The Experiment}

The paper-and-pencil experiment was conducted at the University of Ghana at Legon (Accra) in October 2005. The experiment's administration was facilitated through the use of a booklet ${ }^{13}$ handed out to each subject. The booklet contained the actual experimental design, which consisted of two treatments, one where subjects were asked to state their preference through the indication of a price, (henceforth Treatment 1) and one where they were asked to do so by choosing between two alternatives (henceforth Treatment 2). The whole procedure was carefully explained to all participants before starting the experiments.

38 subjects, each handed out with the above-mentioned booklet, participated in the experiment. ${ }^{14}$ Subjects were admitted to only one treatment to avoid anchor effects. More precisely, in both treatments 19 undergraduate and postgraduate students participated. Two additional treatments were run in October 2006 where we interviewed 20 students following a standard CV approach. Each treatment lasted for about an hour.

The issues of subject pool and sample size deserve some further attention. As aforementioned, we do not believe that these students are wholly representative of the Ghanaian society; we are very much aware of the fact that higher education in Ghana is costly and that students are thus generally from families which are, at least to a limited extent, better-off. Even so, we believe that university students are most likely to produce, in the future, the new leadership class of the country; a leadership able to influence the ideas and patterns of behaviours of local communities, either through a direct participation in policymaking processes - for instance, as politicians - or through a grassroot type of activism - for instance, as tribal chiefs or as NGO activists. Having this in mind, we shall maintain that the Ghanaian students, who participated in the experiments,

\footnotetext{
${ }^{13}$ The booklet is available from the authors upon request.

${ }^{14}$ Note that we originally recruited 20 students for each treatment; however, in each treatment one student did not show up.
} 
while not representative of the entire population, are most likely to turn into important agents of change in their society. As such, their valuation of the environment appears to be particularly interesting and pertinent to the question of policymaking. Moreover, the size of the sample is a relevant matter. We wish to underline that although 38 students (19 in each treatment) might appear a rather small sample, it is strictly comparable with most experimental papers (see, for instance, Hey and Orme, Econometrica, 1994; Hey and Morone, Economica, 2004; Turocy, Watson and Battalio, Experimental Economics, 2007; Bullock Rutström, Experimental Economics, 2007). ${ }^{15}$

We shall now describe the way the experiment was conducted: under Treatment 1 subjects were asked to state the price they were willing to pay to buy $q$ organic bananas, where $q \in[1,20] \subset N$. They were requested to state their WTP by filling in a table of the type reported in Box 1.

Please insert in each raw how much you want to pay to buy the indicated amount of Organic and Non Organic Bananas:

\begin{tabular}{|l|l|l|l|l|}
\hline & Organic Bananas & Cedi & Non Organic Bananas & Cedi \\
\hline 1 & 1 banana & & 1 banana & \\
\hline 2 & 2 bananas & 2 bananas & \\
\hline 3 & 3 bananas & 3 bananas & \\
\hline 4 & 4 bananas & 4 bananas & \\
\hline 5 & 5 bananas & 5 bananas & \\
\hline 6 & 6 bananas & 6 bananas & \\
\hline 7 & 7 bananas & 7 bananas & \\
\hline 8 & 8 bananas & 8 bananas & \\
\hline 9 & 9 bananas & 9 bananas & \\
\hline 10 & 10 bananas & 10 bananas & \\
\hline 11 & 11 bananas & 11 bananas & \\
\hline 12 & 12 bananas & 12 bananas & \\
\hline 13 & 13 bananas & 13 bananas & \\
\hline 14 & 14 bananas & 14 bananas & \\
\hline 15 & 15 bananas & 15 bananas & \\
\hline 16 & 16 bananas & 16 bananas & \\
\hline 17 & 17 bananas & 17 bananas & \\
\hline
\end{tabular}

${ }^{15}$ As already mentioned, our experiment is an individual decision making experiment, i.e. there is no interaction among subjects. Hence, each subject represents an independent observation. 


\begin{tabular}{|l|l|l|l|}
\hline 18 & 18 bananas & 18 bananas & \\
\hline 19 & 19 bananas & 19 bananas & \\
\hline 20 & 20 bananas & 20 bananas & \\
\hline
\end{tabular}

Box 1: Price-organic, table filled-in by subjects

Under Treatment 2, on the other hand, subjects were asked to choose between $q$ organic bananas and $(q+i)$ non-organic bananas, where $q \in[1,10] \subset N$, and $i \in[1,10] \subset N$. Subjects were requested to state their choices by filling in a table of the type reported in Box 2. ${ }^{16}$

\begin{tabular}{|l|l|l|l|}
\hline $\mathbf{N}$ & Organic Banana & Non-organic banana & \\
\hline 1 & 1 banana & 6 bananas & \\
\hline 2 & 2 bananas & 7 bananas & \\
\hline 3 & 3 bananas & 8 bananas & \\
\hline 4 & 4 bananas & 9 bananas & \\
\hline 5 & 5 bananas & 10 bananas & \\
\hline 6 & 6 bananas & 11 bananas & \\
\hline 7 & 7 bananas & 12 bananas & \\
\hline 8 & 8 bananas & 13 bananas & \\
\hline 9 & 9 bananas & 14 bananas & \\
\hline 10 & 10 bananas & 15 bananas & \\
\hline
\end{tabular}

Box 2: Choice-organic ( $\mathrm{i}=5$ ), table filled-in by subjects

In both treatments we used incentive compatible elicitation mechanisms. Subject reservation price was elicited with the Becker-DeGroot-Marschak mechanism, where each subject had to state his/her real WTP for the organic good. More concretely, once subjects have handed in their booklets, the experimenter randomly selected a subject who got the right to play the game: in Treatment 1 the subjects randomly picked up had to buy the banana/s at his/her stated price; in Treatment 2 the subjects randomly picked up was paid according to the choice made in the experiment (i.e. received the banana/s chosen). All other subjects received approximately $\$ 3.3$

\footnotetext{
${ }^{16} \mathrm{We}$ are aware that this is not the conventional dichotomous choice used in contingent valuation experimental design, but since the two goods in question differ only in one attribute (their being organic or not), we shall maintain that our design is better suited to elicit subjects' preferences towards organic goods.
} 
(30,000 cedi) as participation fee. As noted earlier, the whole procedure was carefully explained to all participants before starting the experiments.

\section{Results}

We will now report the main results obtained in the experiment. As mentioned earlier we attempted to elicit the real extra premium that subjects, as consumers, are willing to pay for green products (organic bananas) in Ghana. In figures 1 and 2 we report subjects' willingness to pay for a growing number of respectively organic and non-organic bananas. Consequently the slopes of these curves $(\lambda)$ represent the reservation prices attributed by players to both organic and nonorganic bananas. As we can see, the slope of these curves is almost constant as the curves tend to be linear in fashion. This suggests that under the assumption of linearity, marginal price (i.e. the reservation price for each additional unit of the good considered) and average price coincide. Moreover, this implies that the marginal price expressed by subjects is independent from the quantity acquired, suggesting that players do not show the occurrence of income or substitution effects. Note that this finding should not come as a surprise given the relatively small number of bananas offered in our experiment.

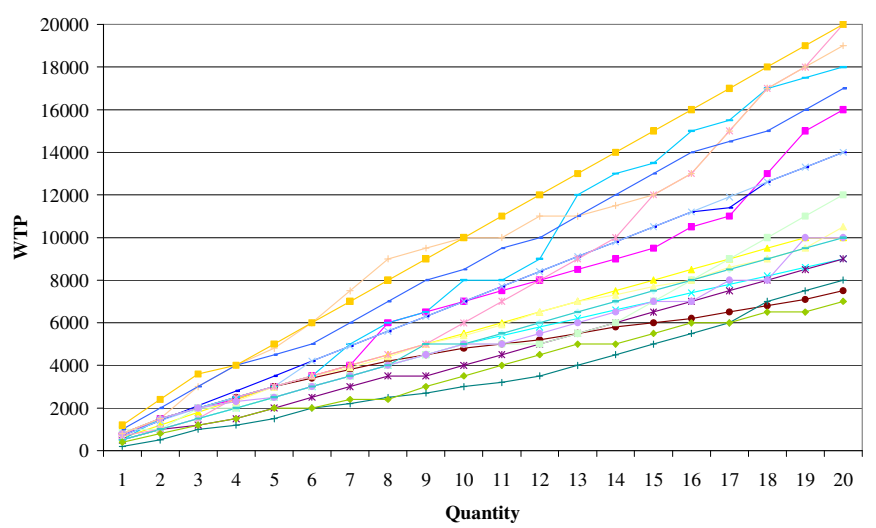

Figure 1: Subjects' willingness to pay for organic products (price-organic)

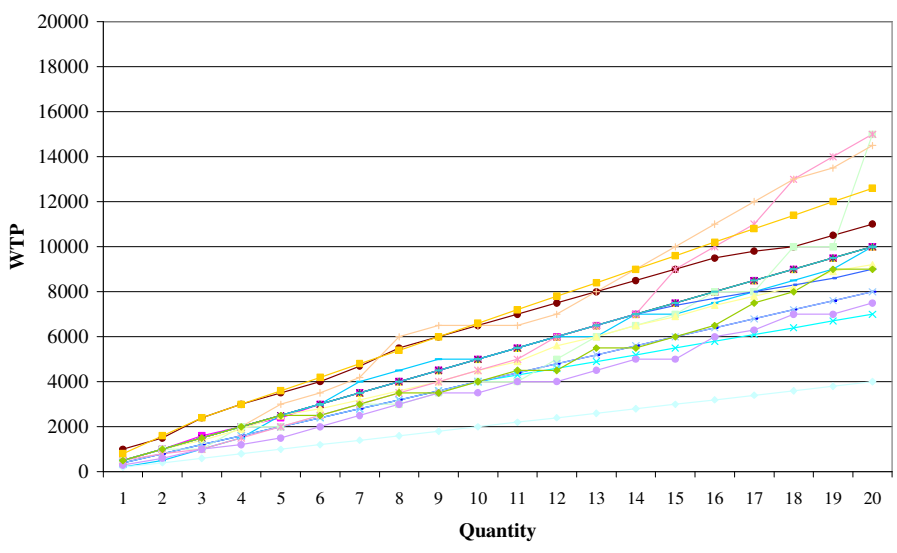

Figure 2: Subjects' willingness to pay for non-organic products (price-organic) 
Further to this, it is relevant to show how our result counters the Diamond et al. $(1993,1994)$ critique according to which WTP analysis does not pass the adding-up test due to the embedding effect - i.e. that willingness-to-pay is the same whether one or several items are valued. We are not, by any means, maintaining that our result contradicts the overall significance of Diamond et al.'s argument; however, we hold that it does not apply to the specific environmental good considered in this experiment.

We shall now estimate the slope of each curve, under the assumption of linearity, and compare them across subjects. ${ }^{17}$ Note that the price ratio $\left(\frac{\lambda_{\text {organic }}}{\lambda_{\text {non-organic }}}\right)$ calculated subject by subject represents the substitution rate of the two goods. Therefore, this rate can give us a measure of the 'organic premium' i.e. the appreciation of the environment as it is expressed directly by the Ghanaians who participated to the experiment. In other words, looking at these ratios will allow us to verify whether Ghanaians display a preference for green products when compared to nonorganic ones. Note that a substitution rate higher than 1 implies a preference for green products (and, consequently, a higher willingness to pay), whereas a value smaller than 1 implies a preference for non-organic goods. Of course, if the ratio is equal to unity it implies that the two goods are perceived as perfect substitutes in a ratio of 1 to 1 .

The data displayed in table 1 shows that in 13 out of 19 cases subjects exhibit a preference for organic goods. This finding suggests that almost 68.5 percent of the players that took part at the experiment expressed a preference for environmentally-friendly goods (i.e. organic bananas). This awareness to environmental issues results in the willingness to pay, on average, 20 percent

\footnotetext{
${ }^{17}$ We do this by means of OLS estimates.
} 
more for green products. If we consider the premium only for those subjects who have stated a preference for green products, than the figure goes up to around 35 percent. ${ }^{18}$

\begin{tabular}{cccc}
\hline Subjects & $\lambda_{\text {organic }}$ & $\lambda_{\text {non-organic }}$ & substitution rate \\
\hline 1 & 700.800 & 499.930 & 1.402 \\
2 & 532.400 & 500.000 & 1.065 \\
3 & 467.420 & 367.420 & 1.272 \\
4 & 433.830 & 500.000 & 0.868 \\
5 & 411.500 & 593.620 & 0.693 \\
6 & 349.790 & 500.000 & 0.700 \\
7 & 697.040 & 400.000 & 1.743 \\
8 & 806.450 & 485.440 & 1.661 \\
9 & 463.420 & 200.000 & 2.317 \\
10 & 465.160 & 511.150 & 0.910 \\
11 & 482.970 & 460.310 & 1.049 \\
12 & 647.080 & 400.000 & 1.618 \\
13 & 726.100 & 612.400 & 1.186 \\
14 & 440.980 & 363.900 & 1.212 \\
15 & 839.870 & 678.710 & 1.237 \\
16 & 793.210 & 477.530 & 1.661 \\
17 & 465.160 & 500.000 & 0.930 \\
18 & 332.340 & 429.090 & 0.775 \\
19 & 928.230 & 643.620 & 1.442 \\
\hline
\end{tabular}

Table 1: Organic-non organic substitution rate (choice-organic)

We shall now compare these findings with those obtained in Treatment 2. Looking at figure 3, we have a very clear picture: 36.84 percent of the subjects always chose the organic product, while 26.32 percent always preferred the non-organic product. Slightly more than one fifth of all subjects (21.05 percent) first expressed their preference for the organic product and subsequently, once the number of non-organic bananas was sufficiently high (i.e. when the $i$ value was sufficiently high), switched to the non-organic product. Three subjects seem to be inconsistent

\footnotetext{
${ }^{18}$ We note that this finding, obtained through an incentive-compatible experiment in a laboratory environment, confirms previous results obtained using a WTP survey approach. The already cited study of Al-Hassan and Jatoe (2005) found that consumers interviewed in the capital Accra were willing to pay 20 percent more for a germ-free cabbage and almost 30 percent more for a pesticide-free one. It should be stressed, however, that while the aforementioned study was focused on the health implications of pesticide use, our study investigated attitudes towards environmentally-sound practices, where human health implications are only but one element.
} 
since they do not respect transitivity (e.g. after having first stated their preference for 2 nonorganic bananas over 1 organic banana, they switched their preferences to 1 organic banana over 3 non-organic bananas).

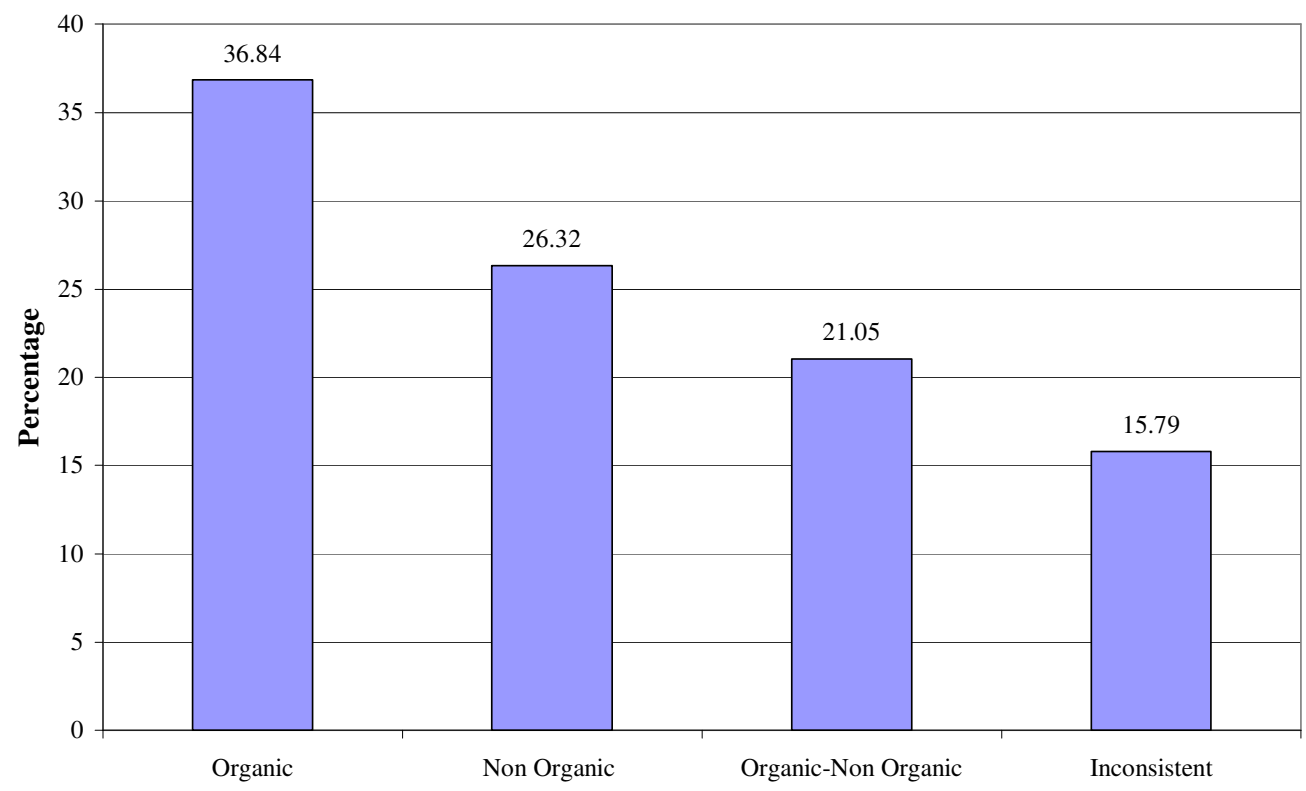

Figure 3: Subjects' categorisation in the choice data experiment (choice-organic)

Overall, these results confirm our earlier findings (i.e. Treatment 1): almost 58 percent of the experimental subjects ${ }^{19}$ displayed a preference for organic products, out of which 36.84 percent showed a persistent preference for organic products (i.e. regardless of the number of extra nonorganic bananas offered during the experiment). ${ }^{20}$

All in all, we can conclude that also by looking at choice data we get a confirmation to our hypothesis. Moreover, as noted earlier, only few subjects provided inconsistent answers (3 out of

\footnotetext{
${ }^{19}$ This percentage goes up to 68.74 if we exclude those three agents who showed an inconsistent behaviour. Interestingly enough, this percentage is exactly the same as the one obtained with price data.

${ }^{20}$ Note that typically, Ghanaians prefer the small non-organic bananas that, they claim, are sweeter. This preference is also explainable by the fact that the bigger, organic bananas are normally exported, so as to satisfy preferences of developed countries consumers and not local. Assuming that also the participants in the experiment tend to prefer the non-organic bananas for their sweetness, we can conclude that our results - where a clear preference towards organic bananas has been observed - are even more significant.
} 
38 if we consider both experimental sessions). This suggests that students involved in the experiment have clearly understood the type of experiment they took part in and that the incentive scheme was appropriate (hence, the standard preferences elicitation techniques in an incentive-compatible experiment turned out to be an adequate tool to elicit Ghanaians preferences towards the environment).

In general, choice experiments, though simpler to understand, provide less information if compared to price experiments. In fact, with choice data we cannot calculate the exact substitution rate of the two goods. We can, however, calculate the threshold value above which agents are willing to opt for one good or the other. In table 2 we report these threshold values calculated for each subject. ${ }^{21}$ First, we observe that such threshold is not calculable for those players who were earlier classified as inconsistent as they move back and forth from such threshold. Second, we can see that for seven subjects all we can say is that the substitution threshold lies somewhere above the ratio one to 11 ; in fact, we are unable to identify this threshold in our experiment (if existing at all), where the highest substitution rate proposed to players was as high as one to 11 . Third, four players are either indifferent (with a ratio of one) between the two goods or prefer non-organic bananas. Forth, for three agents we can define an interval of substitution included among two adjacent integers. Finally, for one player we can pinpoint the exact substitution rate, under the assumption that random answers within the same $i$ group of questions imply indifference. ${ }^{22}$

\footnotetext{
${ }^{21}$ Note that comparing the substitution rate reported in table 6 and the substitution thresholds reported in table 7, we can observe significant differences. These are, of course, due to the different elicitation methods used in the two sessions.

${ }^{22}$ Recall that in treatment 2 subjects were asked to choose between $q$ organic bananas and $(q+i)$ non-organic bananas, where $q \in[1,10] \subset N$, and $i \in[1,10] \subset N$.
} 


\begin{tabular}{cc}
\hline Subjects & $\begin{array}{c}\text { Threshold of } \\
\text { substitution }\end{array}$ \\
\hline 1 & confused \\
2 & $\mathrm{a}>11$ \\
3 & $3<\mathrm{a}<4$ \\
4 & $\mathrm{a}>11$ \\
5 & $\mathrm{a}>11$ \\
6 & $\mathrm{a}=2$ \\
7 & confused \\
8 & $\mathrm{a}>11$ \\
9 & $4<\mathrm{a}<5$ \\
10 & $\mathrm{a}<2$ \\
11 & $\mathrm{a}<2$ \\
12 & $\mathrm{a}<2$ \\
13 & $\mathrm{a}<2$ \\
14 & $\mathrm{a}>11$ \\
15 & $\mathrm{a}>11$ \\
16 & $6<\mathrm{a}<7$ \\
17 & confused \\
18 & $\mathrm{a}<2$ \\
19 & $\mathrm{a}>11$ \\
\hline
\end{tabular}

Table 2: Organic-non organic substitution thresholds (choice-organic)

As already discussed, in this experiment we used an incentive-based mechanism in order to elicit the real willingness to pay for organic bananas which and, we shall maintain, this mechanism turned out to be an adequate tool to elicit Ghanaians preferences towards the environment. For the sake of clarity, we shall now compare these findings with those obtained through standard CV interviews (i.e. where subjects were not faced with a real payment scenario). In table 3 we compare the hypothetical questions results with the incentive-based results. Note that the average price obtained in the incentive compatible experiment is higher than the $\mathrm{CV}$ average price in both treatments. Comparison of simple averages yields calibration factors of 0.674 and 0.668 for organic and non-organic treatments, respectively. Note, moreover, that S.D. is always higher in the CV surveys. Finally, it is worth pointing out that the price elicited through the incentive compatible experiment is closer to the market price. More precisely, the experimental price is higher than the market price for organic bananas (hence displaying the willingness to pay an 
environmental premium) and lower for non-organic bananas. In the CV surveys the average price is always lower than market price.

All in all these two additional treatments show that the CV study without incentive provided results which are less comparable to the market price and with higher standard deviation.

\begin{tabular}{ccccc}
\hline & Average price & S.D. & Average price & S.D. \\
\cline { 2 - 5 } CV & \multicolumn{2}{c}{ Organic Bananas } & \multicolumn{2}{c}{ Non Organic Bananas } \\
\cline { 2 - 5 } Experiment & 415.39 & 230.78 & 316.83 & 131.48 \\
Calibration facor & 613.85 & 205.31 & 475.29 & 122.02 \\
Market Price* & 0.6767 & & 0.6666 & \\
& $\sim 600$ & & $\sim 600$ & \\
\hline
\end{tabular}

* Market price is not precise as it depends on the size of the banana as well as on the quantity of the bananas bought

Table 3: hypothetical questions $v s$. incentive-based experiment

\section{Conclusions}

The aim of this study was to investigate Ghanaians preferences towards the environment; we did so by means of a laboratory experiment conducted at the University of Legon in Accra. Specifically, we set the objective of addressing the hypothesis that Ghanaians display a preference for green products (organic bananas) when compared to non-green products.

Our results suggest that such hypothesis holds in the case of Ghana. In fact, bearing in mind that our experiment has been conducted among University students, whose economic conditions are likely to be above the average Ghanaian, we can affirm that subjects are willing to pay an extra premium for an environmentally-friendly good. This finding counters what Brechin and Kempton have dubbed 'the conventional wisdom', according to which "citizens of developing countries do not or cannot care about the environment" (1994: 247). 
We believe these results are a first step towards a much needed direct elicitation of local preferences towards the environment when formulating policies in LDCs. In terms of implications of our study, we feel that our results should stimulate further research aiming, eventually, at suggesting an environmental policy based on the direct involvement of local stakeholders in the definition of local policies.

\section{REFERENCES}

Al-Hassan, R. and Jatoe, J.B. 2005. Consumer Willingness to Pay for Pesticide-Free and Germ-Free Fresh Vegetables: Perception versus Reality in Accra. Mimeo. University of Ghana in Legon.

Ara, S. 2003. "Consumer Willingness to Pay for Multiple Attributes of Organic Rice: A Case Study in the Philippines". Paper presented at the 25th International Conference of Agricultural Economists, August 16-22, Durban, South Africa.

Becker G., DeGroot, M. and J. Marschak, 1964. "Measuring Utility by a Single Response Sequential Method", Behavioral Science 9, pp. 226-232.

Boccaletti, S., and Nardella, M. 2000. "Consumer willingness to pay for pesticide-free fresh fruit and vegetables in Italy", International Food and Agribusiness Management Review 3, pp. 297-310.

Brechin, S.R. and Kempton, W. 1994. "Global Environmentalism: A Challenge to the Post Materialist Thesis?" Social Science Quarterly, 75:2, pp. 245-269.

Bullock, D. S., and Rutström, E. E., 2007. "Policy making and rent-dissipation: An experimental test", Experimental Economics, Volume 10, Number 1.

Carson R., Wright, J.L., Carson, N.J., Alberini, A. and N.E. Flores, 1995. A Bibliography of Contingent Valuation Studies and Papers. San Diego: Natural Resources Damages Assessment Inc.

Cranfield, J. and Magnusson, E. 2003. “Canadian Consumer's Willingness-To-Pay for Pesticide Free Food Products: An Ordered Probit Analysist", International Food and Agribusiness Management Review 6:4, pp. 13-30. 
Danso, G., Drechsel, P. and S. Pialor, 2002. "Perceptions of organic agriculture by urban vegetable farmers and consumers in Ghana", Urban Agriculture Magazine 6, pp. 23-24.

Dasgupta, S., Laplante, B., Wang, H., and D. Wheeler, 2002. "Confronting the Environmental Kuznets Curve”, Journal of Economic Perspectives 16:1, pp. 147-168.

Diamond, P.A. and Hausman, J.A. 1994. "Contingent Valuation: Is Some Number Better than No Number?” Journal of Economic Perspectives 8:4, pp. 45-64.

Diamond, P.A., Hausman, J.A., Leonard, G.K. and M.A. Denning, 1993. "Does Contingent Valuation Measure Preferences? Experimental Evidence", pp. 41-62 in Hausman, J. (Ed.), Contingent Valuation: A Critical Assessment. Amsterdam, Elsevier Science Publishers.

Gil, J.M., Gracia, A. and M. Sanchez, 2000. "Market Segmentation and Willingness to Pay for Organic Products in Spain”, International Food and Agribusiness Management Review 3, pp. 207-226.

Hey, J.D. and Orme, C. 1994. "Investigating Generalizations of Expected Utility Theory Using Experimental Data", Econometrica 62:6, pp. 1291-1326.

Hey, J. D. and Morone, A. 2004. "Do Markets Drive Out Lemmings-or Vice Versa?”, Economica, vol. 71(284), pages 637-659.

Hey, J.D., Morone, A. and U. Schmidt, 2007. "Noise and Bias in Eliciting Preferences", Discussion Papers in Economics 2007/04, University of York.

Hirschman, A. O. 1970. “Exit, Voice and Loyalty”, Harvard University Press.

Kinnear, T.C. and Taylor, R.J. 1973. "The Effect of Ecological Concern on Brand Perceptions", Journal of Marketing Research 10, pp. 191-197.

Levitt, S.D. and List, J.A. 2007. "What Do Laboratory Experiments Measuring Social Preferences Reveal About the Real World?", Journal of Economic Perspectives 21:2, pp. 153-174.

Martin, B. and Simintiras, A.C. 1995. "The Impact of Green Product Lines on the Environment: Does what They Know Affect How They Feel?", Marketing Intelligence and Planning 13, pp. 16-23.

Martinez-Alier, J. 1995. “The Environment as a Luxury Good or 'Too Poor to be Green"”. Ecological Economics 13, pp. 1-10. 
Morone, A. and Schmidt, U. 2003. An Experimental Investigation of Alternatives to Expected Utility Using Pricing Data, University of Hannover Discussion Paper No 28.

Ozanne, L.K. and Vlosky, R.P. 2003. "Certification from the US Consumer Perspective: A Comparison of 1995 and 2000", Forest Products Journal 53:3, pp. 13-21.

Panayotou, T. 1993. "Empirical Tests and Policy Analysis of Environmental Degradation at different Stages of Economic Development", Working Paper WP238, Technology and Employment Programme, ILO, Geneva.

Pearce, D.W. and Turner, K.R. 1990. Economics of Natural Resources and the Environment, Baltimore: Johns Hopkins University Press.

Prothero, A. and McDonagh, P. 1993. "The European Community and Environmentalism: The Impact of EC Environmental Policies upon the Marketing Function” pp. 985-1004 in Baker, M.J. (Ed.) Perspectives on Marketing Management Vol. 3. Chichester: Wiley.

Samuelson, L. 2005. "Economic Theory and Experimental Economics", Journal of Economic Literature, 43:1, pp. 65-107.

Scialabba, N. 2000. "Factors Influencing Organic Agriculture Policies with a Focus on Developing Countries”, IFOAM 2000 Scientific Conference, Basel, Switzerland, 28-31 August. Available online at: www.fao.org/organicag/doc/BaselSum-final.doc. Accessed on: 01.09.2006.

Siaw, G.K., 2003. "Fair Trade Bananas: Contributing to Sustainable Rural Livelihoods in Ghana". World Trade Organization Public Symposium: Challenges Ahead on the Road to Cancun, Geneva, June $16-18$.

Smith, Vernon L. (1976). "Experimental Economics: Induced Value Theory". American Economic Review 66 (2): $274-279$

Thurow, L. 1980. The Zero-Sum Society: Distribution and the Possibilities for Change. New York: Basic Books.

Turocy, T., Watson, E., and Battalio, R. C., 2007. "Framing the First-Price Auction", Experimental Economics 10(1): 37-52, 2007. 
VREL (Volta River Estates Limited). Banana Production. Available online at: http://www.voltariver.com/.

WEFA (Wharton Econometric Forecasting Associates), 2001. Ghana Country Monitor. March.

Whittington, D. 2002. "Improving the Performance of Contingent Valuation Studies in Developing Countries", Environmental and Resource Economics 22, pp. 323-367.

Willer, H. \& Yussefi, M. (Eds.), 2004. The World of Organic Agriculture: Statistics and Emerging Trends, 2004. Bonn: International Federation of Organic Agriculture Movements.

Wolf, M. 2004. Why Globalisation Works? The Case for Global Market Economy. New Haven: Yale University Press. 